
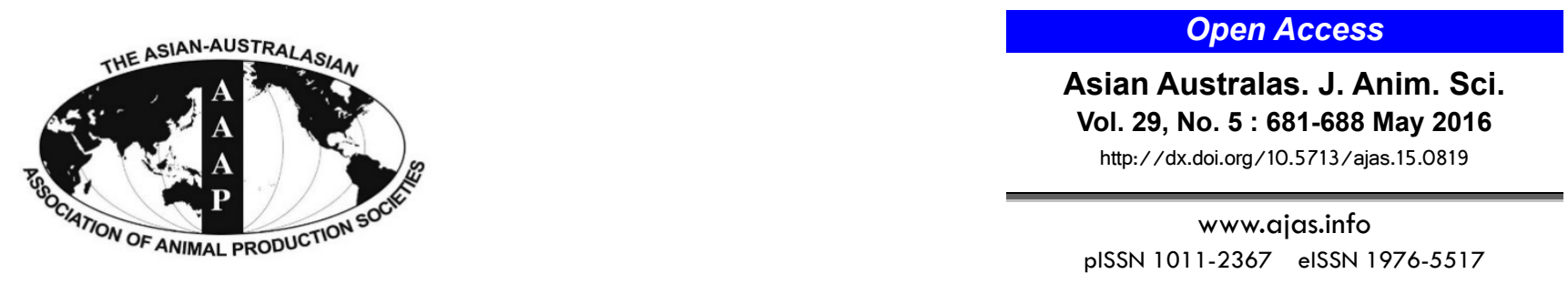

\title{
A Comparison of Natural (D- $\alpha$-tocopherol) and Synthetic (DL-a-tocopherol Acetate) Vitamin E Supplementation on the Growth Performance, Meat Quality and Oxidative Status of Broilers
}

\author{
K. Cheng, Y. Niu, X. C. Zheng, H. Zhang, Y. P. Chen, M. Zhang ${ }^{1}$, X. X. Huang ${ }^{1}$, \\ L. L. Zhang, Y. M. Zhou, and T. Wang* \\ College of Animal Science and Technology, Nanjing Agricultural University, Nanjing 210095, China
}

\begin{abstract}
The present study was conducted to compare the supplementation of natural (D- $\alpha$-tocopherol) and synthetic (DL- $\alpha$ tocopherol acetate) vitamin $\mathrm{E}$ on the growth performance, meat quality, muscular antioxidant capacity and genes expression related to oxidative status of broilers. A total of 1441 day-old Arbor Acres broiler chicks were randomly allocated into 3 groups with 6 replicates of 8 birds each. Birds were given a basal diet (control group), and basal diet supplemented with either 20 IU D- $\alpha$-tocopherol or DL- $\alpha$ tocopherol acetate for 42 days, respectively. The results indicated that treatments did not alter growth performance of broilers ( $p>0.05$ ). Compared with the control group, concentration of $\alpha$-tocopherol in the breast muscle was increased by the supplementation of vitamin $\mathrm{E}$ $(\mathrm{p}<0.05)$. In the thigh, $\alpha$-tocopherol content was also enhanced by vitamin $\mathrm{E}$ inclusion, and this effect was more pronounced in the natural vitamin E group $(p<0.05)$. Vitamin E supplementation increased the redness of breast $(p<0.05)$. In the contrast, the inclusion of synthetic vitamin $\mathrm{E}$ decreased lightness of thigh $(\mathrm{p}<0.05)$. Dietary vitamin E inclusion reduced drip loss at $24 \mathrm{~h}$ of thigh muscle $(\mathrm{p}<0.05)$, and this effect was maintained for drip loss at $48 \mathrm{~h}$ in the natural vitamin $\mathrm{E}$ group $(\mathrm{p}<0.05)$. Broilers given diet supplemented with vitamin $\mathrm{E}$ showed decreased malondialdehyde (MDA) content in the breast $(\mathrm{p}<0.05)$. Additionally, natural rather than synthetic vitamin $E$ reduced MDA accumulation in the thigh $(p<0.05)$. Neither natural nor synthetic vitamin E supplementation altered muscular mRNA abundance of genes related to oxidative stress ( $>0.05$ ). It was concluded that vitamin E supplementation, especially the natural vitamin E, can enhance the retention of muscular $\alpha$-tocopherol, improve meat quality and muscular antioxidant capacity of broilers. (Key Words: D- $\alpha$-tocopherol, DL- $\alpha$-tocopherol Acetate, Meat Quality, Oxidative Status, Broiler)
\end{abstract}

\section{INTRODUCTION}

Lipid oxidation is one of the major causes of quality deterioration in meat and meat products. This oxidation can lead to serious consequences for meat quality, including the production of off-flavors and odors, reduction of polyunsaturated fatty acids, fat-soluble vitamins and pigments, lower consumer acceptability, and the generation of compounds such as peroxides and aldehydes which may be toxic (Morrissey et al., 1994). Vitamin E as a lipid

\footnotetext{
* Corresponding Author: T. Wang. Tel: +86-25-84396067, Fax:

+86-25-84395156, E-mail: tianwangnjau@163.com

1 Jiangsu Wilmar Spring Fruit Nutrition Products Co., Ltd. Taixing 225434, China.

Submitted Oct. 1, 2015; Revised Nov. 15, 2015; Accepted Jan. 15, 2016
}

component of biological membranes is known to be a major chain-breaking antioxidant (Sahin et al., 2002). Various studies have demonstrated that vitamin E can improve meat quality and inhibit lipid oxidation of muscles in broilers (O'neill et al., 1998; Voljč et al., 2011; Rey et al., 2015).

Eight naturally occurring substances have been found to have vitamin E activity: $\alpha$-, $\beta-, \gamma$-, and $\delta$-tocopherols and $\alpha$-, $\beta-, \gamma$-, and $\delta$-tocotrienols (Voljč et al., 2011). Of these the $\alpha$ tocopherol is the most biologically active and most widely distributed form (Halliwell and Gutteridge, 2000). This molecule possesses three centers where stereoisomers can occur, and the naturally occurring molecule is the $\mathrm{D}-\alpha$ tocopherol (RRR- $\alpha$-tocopherol) configuration that has the highest vitamin activity (McDonald et al., 2011). Synthetic DL- $\alpha$-tocopherol acetate (all racemic $\alpha$-tocopherol acetate) 
consisting of all eight possible stereoisomers is commonly used as a vitamin E supplement in poultry feeds. Previous studies have shown that D- $\alpha$-tocopherol exhibited a superior bioavailability than the synthetic DL- $\alpha$-tocopherol acetate in retaining in tissues (Lauridsen et al., 2002), alleviating lipopolysaccharide-induced inflammatory response (Kaiser et al., 2012), and improving meat quality and muscular antioxidant capacity (Boler et al., 2009; Voljč et al., 2011; Rey et al., 2015). However, in broilers, limit was known about the use of D- $\alpha$-tocopherol as an alternative for the synthetic vitamin $\mathrm{E}$ on the muscular oxidative status, and especially meat quality and muscular mRNA abundance of genes involved in antioxidant system. The present study was therefore conducted to compare the supplementation of $D$ - $\alpha$-tocopherol and DL- $\alpha$-tocopherol acetate on the growth performance, meat quality, muscular antioxidant capacity and genes expression related to oxidative status of broilers.

\section{MATERIAL AND METHODS}

\section{Experimental design, diets and management}

All experimental conditions and animal procedures were approved by Nanjing Agricultural University Institutional Animal Care and Use Committee. A total of 1441 day-old Arbor Acres broiler chicks obtained from a commercial hatchery (Hewei Co., Ltd, Anhui, China) were randomly allocated into 3 groups with 6 replicates of 8 birds each (one replicate per cage, 4 males and 4 females per cage). Birds were given a basal diet (control group), and basal diet supplemented with either 20 IU D- $\alpha$-tocopherol or DL- $\alpha$ tocopherol acetate for 42 days, respectively. D- $\alpha$-tocopherol was provided by Jiangsu Wilmar Spring Fruit Nutrition Products Co., Ltd. (Taixing, Jiangsu, China) with the purity of $6 \%$. DL- $\alpha$-tocopherol was purchased from Zhejiang NVB Co., Ltd (Xinchang, Zhejiang, China), and the purity was $50 \%$. The basal diet was formulated according to the NRC (1994) to meet the nutrient requirements of the broiler. The analyzed $\alpha$-tocopherol in the basal grower ( 1 to 21 day) and finisher (22 to 42 day) diet was 7.12 and $8.96 \mathrm{mg} / \mathrm{kg}$, respectively. Formulation and nutrient level of basal diet are presented in Table 1. Birds had free access to mash feed and water in 3-layer cages in a temperature-controlled room with continuous lighting. The temperature of the room was maintained at $32^{\circ} \mathrm{C}$ to $34^{\circ} \mathrm{C}$ for the first 3 day and then reduced by $2^{\circ} \mathrm{C}$ to $3^{\circ} \mathrm{C}$ per week to a final temperature of $20^{\circ} \mathrm{C}$. At 21 and 42 day of age, birds were weighed after feed deprivation for $12 \mathrm{~h}$ with water being provided ad libitum. Feed intake was recorded by replicate (cage) to calculate average daily feed intake (ADFI), average daily gain (ADG), and feed/gain ratio (F:G). Birds that died during the experiment were weighed, and the data were included in the calculation of $F: G$.
Table 1. Composition and nutrient level of basal diet $(\mathrm{g} / \mathrm{kg}$, as fed basis unless otherwise stated)

\begin{tabular}{|c|c|c|}
\hline$\overline{\text { Items }}$ & 1 to $21 \mathrm{~d}$ & 22 to $42 \mathrm{~d}$ \\
\hline \multicolumn{3}{|l|}{ Ingredients } \\
\hline Corn & 576.1 & 622.7 \\
\hline Soybean meal & 310 & 230 \\
\hline Corn gluten meal & 32.9 & 60 \\
\hline Soybean oil & 31.1 & 40 \\
\hline Limestone & 12 & 14 \\
\hline Dicalcium phosphate & 20 & 16 \\
\hline L-Lysine & 3.4 & 3.5 \\
\hline DL-Methionine & 1.5 & 0.8 \\
\hline Sodium chloride & 3 & 3 \\
\hline Premix $^{1}$ & 10 & 10 \\
\hline \multicolumn{3}{|l|}{ Calculated nutrient levels ${ }^{2}$} \\
\hline $\begin{array}{l}\text { Apparent metabolizable energy } \\
(\mathrm{MJ} / \mathrm{kg})\end{array}$ & 12.56 & 13.19 \\
\hline Crude protein & 211 & 196 \\
\hline Calcium & 10.00 & 9.50 \\
\hline Available phosphorus & 4.60 & 3.90 \\
\hline Lysine & 12.00 & 10.50 \\
\hline Methionine & 5.00 & 4.20 \\
\hline Methionine + cystine & 8.50 & 7.60 \\
\hline \multicolumn{3}{|l|}{ Analyzed composition ${ }^{3}$} \\
\hline Crude protein & 208 & 192 \\
\hline Ash & 57.2 & 56.5 \\
\hline
\end{tabular}

${ }^{1}$ Premix provided per kilogram of diet: transretinyl acetate, $3.44 \mathrm{mg}$; cholecalciferol, $0.075 \mathrm{mg}$; menadione, $1.3 \mathrm{mg}$; thiamin, $2.2 \mathrm{mg}$; riboflavin, $8 \mathrm{mg}$; nicotinamide, $40 \mathrm{mg}$; choline chloride, $400 \mathrm{mg}$; calcium pantothenate, $10 \mathrm{mg}$; pyridoxine $\cdot \mathrm{HCl}, 4 \mathrm{mg}$; biotin, $0.04 \mathrm{mg}$; folic acid, $1 \mathrm{mg}$; vitamin $\mathrm{B}_{12}$ (cobalamin), $0.013 \mathrm{mg}$; Fe (from ferrous sulfate), $80 \mathrm{mg} ; \mathrm{Cu}$ (from copper sulphate), $8.0 \mathrm{mg} ; \mathrm{Mn}$ (from manganese sulphate), $110 \mathrm{mg}$; Zn (from zinc oxide), $60 \mathrm{mg}$; I (from calcium iodate), $1.1 \mathrm{mg}$; $\mathrm{Se}$ (from sodium selenite), $0.3 \mathrm{mg}$.

${ }^{2}$ The nutrient levels were as fed basis.

${ }^{3}$ Values based on analysis of triplicate samples of diet.

\section{Sample collection}

At the end of experiment (42 day), 18 male broilers (1 bird per cage) were randomly selected and weighed after withdrawal of feed for $12 \mathrm{~h}$. Birds were killed by cervical dislocation after bleeding from jugular veins. About $3 \mathrm{~g}$ breast and thigh samples were then immediately collected and stored at $-80^{\circ} \mathrm{C}$ for further mRNA abundance determination and antioxidant parameters. After that, breast and thigh muscles were excised for meat quality measurement. The left-side muscle was used for the assay of $\mathrm{pH}$ value and meat color, and the right-side muscle was used to determine drip loss and cooking loss.

\section{Meat quality assay}

The meat color was measured at $24 \mathrm{~h}$ postmortem by a colorimeter (Minolta CR-10, Konica Minolta Sensing, Osaka, Japan) according to CIELAB system ( $\mathrm{L}^{*}=$ lightness; $\mathrm{a}^{*}=$ redness; $\mathrm{b}^{*}=$ yellowness $)$. The $\mathrm{pH}$ values of muscles 
at $45 \mathrm{~min}\left(\mathrm{pH}_{45} \min \right)$ and $24 \mathrm{~h}\left(\mathrm{pH}_{24 \mathrm{~h}}\right)$ postmortem were measured at a $1 \mathrm{~cm}$ depth using a $\mathrm{pH}$ meter (HI9125, HANNA Instruments, Clujnapoca, Romania). Drip loss of muscle was measured according to method of Zhang et al. (2015). Briefly, around size of $3 \mathrm{~cm}$ (length) $\times 2 \mathrm{~cm}$ (width) $\times 1 \mathrm{~cm}$ (thickness) muscle samples trimmed of adjacent fat and connective tissues were weighed, suspended in plastic bag, sealed, and stored at $4^{\circ} \mathrm{C}$ for $24 \mathrm{~h}$ and $48 \mathrm{~h}$. After $24 \mathrm{~h}$ and $48 \mathrm{~h}$ at $4^{\circ} \mathrm{C}$, the samples were reweighed to calculate drip loss. For the determination of cooking loss, approximately $15 \mathrm{~g}$ muscle sample was weighed, held in plastic bags, and immersed in a water bath at $80^{\circ} \mathrm{C}$ until the internal temperature reached $75^{\circ} \mathrm{C}$. After that, samples were reweighed to calculate the drip loss of muscle after cooling to room temperature.

\section{Preparation of muscular homogenate}

Approximately $0.3 \mathrm{~g}$ of muscle samples were homogenized (1:4, wt/vol) with ice-cold $154 \mathrm{mmol} / \mathrm{L}$ sodium chloride solution using an Ultra-Turrax homogenizer (Tekmar Co., Cicinati, OH, USA), and then centrifuged at $4,550 \mathrm{~g}$ for $15 \mathrm{~min}$ and at $4^{\circ} \mathrm{C}$. The supernatant was used for determination of $\alpha$-tocopherol and antioxidant parameters.

\section{Measurement of $\alpha$-tocopherol}

Muscular $\alpha$-tocopherol was determined according to the method described by Zhang et al. (2009) with modifications. In detail, a $2 \%$ solution pyrogallol in ethanol was slowly added to $(5 \mathrm{~mL})$ muscular homogenate $(0.5 \mathrm{~mL})$ while mixing, and the mixture was then heated for $2 \mathrm{~min}$ in a $70^{\circ} \mathrm{C}$ shaking water bath. Then, $0.25 \mathrm{~mL}$ of saturated $\mathrm{KOH}$ was added to the mixture. The mixture was heated again in a $70^{\circ} \mathrm{C}$ shaking water bath for $30 \mathrm{~min}$ and next placed in an ice bath after saponification. Hexane $(2 \mathrm{~mL})$ and water $(0.5$ $\mathrm{mL}$ ) were added to the saponified samples, which were then shaken vigorously for $2 \mathrm{~min}$. After that, $1 \mathrm{~mL}$ of the hexane layer was transferred to a $4-\mathrm{mL}$ glass test tube for analysis. Standards solutions of $\alpha$-tocopherol were also prepared. A $0.2 \%$ bathophenanthroline solution $(200 \mu \mathrm{L})$ was then added to all the samples and thoroughly mixed. $200 \mu \mathrm{L}$ of 1 $\mathrm{mmol} / \mathrm{L} \mathrm{FeCl}_{3}$ solution was added and samples were vortexed. After $1 \mathrm{~min}, 200 \mu \mathrm{L}$ of an $\mathrm{H}_{3} \mathrm{PO}_{4}$ solution was added and vortexed again. Absorbance of final solutions was read on a spectrophotometer at $534 \mathrm{~nm}$ (Mapada Instruments Co., Ltd., Shanghai, China). The standard curve was used to calculate the concentration of $\alpha$-tocopherol in each sample. The concentrations of $\alpha$-tocopherol were expressed as microgram per gram of fresh muscle.

\section{Determination of antioxidant parameters}

Muscular homogenate was used to determine the activities of total antioxidant capacity (T-AOC), total superoxide dismutase (T-SOD) and glutathione peroxidase (GSH-PX), and the content of malondialdehyde (MDA) and total protein by commercial kits according to the instructions of the manufacture (Nanjing Jiancheng Institute of Bioengineering, Nanjing, Jiangsu, China). T-AOC was measured based on the method of Benzie and Strain (1996). One unit of T-AOC was defined as the amount of enzyme per milligram protein which would increase the absorbance by 0.01 at $37^{\circ} \mathrm{C}$ in $1 \mathrm{~min}$. The activity of SOD was determined using the hydroxylamine method (Ōyanagui, 1984), and one unit of SOD activity was defined as the amount of enzyme per milligram protein of muscle that produced $50 \%$ inhibition of the rate of nitrite generation at $37^{\circ} \mathrm{C}$. GSH-PX activity was determined by dithio-nitro benzene method (Hafeman et al., 1974), and one unit of GSH-PX activity was defined as the amount of enzyme per milligram protein that would catalyze the conversion of 1 $\mu \mathrm{mol} / \mathrm{L}$ of reduced glutathione to oxidized glutathione at $37^{\circ} \mathrm{C}$ in $5 \mathrm{~min}$. MDA concentration was measured using thiobarbituric acid method (Placer et al., 1966). All results were normalized against total protein concentration in each sample for inter-sample comparison.

\section{Total RNA isolation and mRNA quantification}

The abundance of muscular mRNA was measured according to method of Zhang et al. (2014). RNA was isolated by a TRIzol reagent (TaKaRa Biotechnology, Dalian, Liaoning, China) from muscle sample (breast and thigh) according to protocol of manufacturer. The concentration of RNA and its purity were determined from OD260/280 readings (ratio $>1.8$ ) using a NanoDrop ND1000 UV spectrophotometer (NanoDrop Technologies, Wilmington, DE, USA). After that, $1 \mu \mathrm{g}$ of total RNA was reverse-transcribed into cDNA using the PrimeScript RT reagent kit (TaKaRa Biotechnology, China) according to the instructions of manufacturer. Real-time polymerase chain reaction (PCR) was carried out on an ABI StepOnePlus Real-Time PCR system (Applied Biosystems, Grand Island, NY, USA) according to the manufacturer's guidelines. The primer sequences for the target and reference genes (nuclear factor erythroid 2-related factor 2 [ $N r f 2]$, heme oxygenase 1 [HO-1], superoxide dismutase 1 [SOD1], glutathione peroxidase 1 [GPX1], and $\beta$-actin) are shown in Table 2. In detail, the reaction mixture was prepared using $2 \mu \mathrm{L}$ of cDNA, $0.4 \mu \mathrm{L}$ of forward primer, $0.4 \mu \mathrm{L}$ of reverse primer, $10 \mu \mathrm{L}$ of SYBR Premix Ex Taq (TaKaRa Biotechnology, China), $0.4 \mu \mathrm{L}$ of ROX reference dye (TaKaRa Biotechnology, China) and $6.8 \mu \mathrm{L}$ of double-distilled water. Each sample was tested in duplicate. PCR consisted of a pre-run at $95^{\circ} \mathrm{C}$ for $30 \mathrm{~s}$ and 40 cycles of denaturation at $95^{\circ} \mathrm{C}$ for $5 \mathrm{~s}$, followed by a $60^{\circ} \mathrm{C}$ annealing step for $30 \mathrm{~s}$. 
Table 2. Sequences of real-time PCR primers

\begin{tabular}{|c|c|c|c|}
\hline Gene & GeneBank ID & Primer sequence $\left(5^{\prime} \rightarrow 3^{\prime}\right)$ & Product size (bp) \\
\hline \multirow[t]{2}{*}{ Nrf2 } & NM_205117.1 & GATGTCACCCTGCCCTTAG & 215 \\
\hline & & CTGCCACCATGTTATTCC & \\
\hline \multirow[t]{2}{*}{$\mathrm{HO}-1$} & HM237181.1 & GGTCCCGAATGAATGCCCTTG & 138 \\
\hline & & ACCGTTCTCCTGGCTCTTGG & \\
\hline \multirow[t]{2}{*}{ SOD1 } & NM_205064.1 & CCGGCTTGTCTGATGGAGAT & 124 \\
\hline & & TGCATCTTTTGGTCCACCGT & \\
\hline \multirow[t]{2}{*}{$G P X 1$} & NM_001277853.1 & GACCAACCCGCAGTACATCA & 205 \\
\hline & & GAGGTGCGGGCTTTCCTTTA & \\
\hline \multirow[t]{2}{*}{$\beta$-actin } & NM_205518.1 & TGCTGTGTTCCCATCTATCG & 150 \\
\hline & & TTGGTGACAATACCGTGTTCA & \\
\hline
\end{tabular}

PCR, polymerase chain reaction; Nrf2, nuclear factor erythroid 2-related factor 2; HO-1, heme oxygenase 1; SOD1, superoxide dismutase 1; GPX1, glutathione peroxidase 1 .

The conditions of the melting curve analysis were as follows: one cycle of denaturation at $95^{\circ} \mathrm{C}$ for $10 \mathrm{~s}$, followed by an increase in temperature from $65^{\circ} \mathrm{C}$ to $95^{\circ} \mathrm{C}$ at a rate of $0.5^{\circ} \mathrm{C} / \mathrm{s}$. The relative levels of mRNA expression were calculated using the $2^{-\Delta \Delta \mathrm{C}} \mathrm{T}$ method (Livak and Schmittgen, 2001) after normalization against the reference gene $\beta$-actin. The values of broilers in the control group were used as a calibrator.

\section{Statistical analysis}

Data were analyzed by one-way analysis of variance using SPSS statistical software (Ver.16.0 for windows, SPSS Inc., Chicago, IL, USA). Differences among treatments were examined using Duncan's multiple range tests. The differences were considered to be significant at $\mathrm{p}<0.05$. Data are presented as means and their pooled standard errors.

\section{RESULTS}

\section{Growth performance}

As indicated in Table 3, broilers fed diets supplemented with vitamin $E$ exhibited similar growth performance (ADG, ADFI, and F:G) to those given basal diet during the 42-day study $(\mathrm{p}>0.05)$.

\section{Muscular $\alpha$-tocopherol retention}

Compared with the control group (Table 4), the concentration of $\alpha$-tocopherol in the breast muscle was significantly increased by the supplementation of vitamin $\mathrm{E}$ $(p<0.05)$, but the content of $\alpha$-tocopherol in the breast was not affected by vitamin E source $(p>0.05)$. In the thigh, the concentration of $\alpha$-tocopherol was also significantly enhanced by vitamin $\mathrm{E}$ inclusion, and this effect was more pronounced in the natural vitamin $\mathrm{E}$ group $(\mathrm{p}<0.05)$.

\section{Meat quality}

Vitamin E supplementation (Table 5) in either natural or synthetic form significantly increased the redness of breast $(p<0.05)$ when compared with the control group, whereas no difference was observed in the redness of breast between the natural and synthetic vitamin $E$ group $(p>0.05)$. Synthetic vitamin E supplementation also significantly decreased lightness of thigh $(\mathrm{p}<0.05)$, but lightness of thigh was not altered by the form of vitamin $E(p>0.05)$. Dietary vitamin $\mathrm{E}$ supplementation significantly reduced drip loss at $24 \mathrm{~h}$ of thigh muscle $(\mathrm{p}<0.05)$, and this effect was maintained for drip loss at $48 \mathrm{~h}$ in the natural vitamin $\mathrm{E}$ group $(p<0.05)$. However, supplementation of vitamin $\mathrm{E}$ did not alter $\mathrm{pH}$ value, cooking loss and yellowness of muscles (breast and thigh), drip loss and lightness of breast, and the

Table 3. Effects of natural and synthetic vitamin $\mathrm{E}$ on the growth performance of broilers

\begin{tabular}{|c|c|c|c|c|c|c|}
\hline Items & Period (d) & Control $^{1}$ & SVE & NVE & SEM $^{3}$ & p-value \\
\hline \multirow[t]{3}{*}{ ADG (g/bird/per d) } & $1-21$ & 25.6 & 25.5 & 26.1 & 0.3 & 0.756 \\
\hline & $22-42$ & 70.1 & 75.9 & 75.1 & 1.3 & 0.122 \\
\hline & $1-42$ & 48.4 & 51.3 & 51.3 & 0.6 & 0.077 \\
\hline \multirow[t]{3}{*}{ ADFI (g/bird/per d) } & $1-21$ & 40.2 & 39.1 & 39.9 & 0.5 & 0.660 \\
\hline & $22-42$ & 134 & 143 & 133 & 2 & 0.092 \\
\hline & $1-42$ & 88.0 & 91 & 87 & 1 & 0.132 \\
\hline \multirow[t]{3}{*}{$\mathrm{F}: \mathrm{G}(\mathrm{g}: \mathrm{g})$} & $1-21$ & 1.57 & 1.53 & 1.54 & 0.02 & 0.654 \\
\hline & $22-42$ & 1.92 & 1.88 & 1.91 & 0.02 & 0.791 \\
\hline & $1-42$ & 1.82 & 1.78 & 1.79 & 0.01 & 0.604 \\
\hline
\end{tabular}

SEM, pooled standard error of the means; ADG, average daily gain; ADFI, average daily feed intake; F:G, feed/gain ratio.

${ }^{1}$ Control, basal diet; SVE, basal diet supplemented with $20 \mathrm{IU} / \mathrm{kg}$ synthetic vitamin E; NVE, basal diet supplemented with $20 \mathrm{IU} / \mathrm{kg}$ natural vitamin E. 
Table 4. Effects of natural and synthetic vitamin $\mathrm{E}$ on the concentration of $\alpha$-tocopherol in muscles f broilers ( $\mu \mathrm{g} / \mathrm{g}$ tissue)

\begin{tabular}{|c|c|c|c|c|c|}
\hline Items & Control $^{1}$ & SVE & NVE & SEM & $\mathrm{p}$-value \\
\hline \multicolumn{6}{|l|}{ Breast } \\
\hline$\alpha$-Tocopherol & $0.57^{\mathrm{b}}$ & $1.81^{\mathrm{a}}$ & $2.32^{\mathrm{a}}$ & 0.28 & 0.001 \\
\hline \multicolumn{6}{|l|}{ Thigh } \\
\hline$\alpha$-Tocopherol & $1.11^{\mathrm{c}}$ & $3.11^{\mathrm{b}}$ & $4.22^{\mathrm{a}}$ & 0.36 & $<0.001$ \\
\hline \multicolumn{6}{|c|}{$\begin{array}{l}\text { SEM, pooled standard error of the means. } \\
1 \text { Control, basal diet; SVE, basal diet supplemented with } 20 \mathrm{IU} / \mathrm{kg} \\
\text { synthetic vitamin E; NVE, basal diet supplemented with } 20 \mathrm{IU} / \mathrm{kg} \text { natural } \\
\text { vitamin E. }\end{array}$} \\
\hline
\end{tabular}

redness of thigh $(\mathrm{p}>0.05)$.

\section{Muscular antioxidant capacity}

Broilers given diet supplemented with (Table 6) either natural or synthetic vitamin E showed decreased MDA content in the breast $(\mathrm{p}<0.05)$ than those given the basal diet. Additionally, natural rather than synthetic vitamin $\mathrm{E}$ reduced MDA accumulation in the thigh $(\mathrm{p}<0.05)$. However, treatments did not alter activities of T-SOD, T-AOC, and GSH-PX ( $p>0.05)$.

\section{Muscular mRNA abundance}

Neither natural nor synthetic vitamin E (Table 7) supplementation altered muscular mRNA abundance including Nrf2, HO-1, GPX1, and SOD1 as compared with the control group $(\mathrm{p}>0.05)$.

\section{DISCUSSION}

Many factors would affect vitamin E requirement, including feed composition, dietary selenium, antioxidant occurred in the feed, fat content and its profile. In this study, neither natural nor synthetic vitamin E supplementation altered the growth performance of broilers, which was in agreement with the results of Sheehy et al. (1991), and
Table 5. Effects of natural and synthetic vitamin E on meat quality of broilers

\begin{tabular}{lccccc}
\hline Items & Control $^{1}$ & SVE & NVE & SEM & p-value \\
\hline Breast & & & & & \\
$\mathrm{pH}_{45 \min }$ & 6.52 & 6.43 & 6.42 & 0.04 & 0.541 \\
$\mathrm{pH}_{24 \mathrm{~h}}$ & 5.79 & 5.85 & 5.84 & 0.01 & 0.218 \\
Lightness & 46.9 & 47.6 & 46.7 & 0.3 & 0.568 \\
Redness & $3.03^{\mathrm{b}}$ & $3.90^{\mathrm{a}}$ & $4.29^{\mathrm{a}}$ & 0.17 & 0.001 \\
Yellowness & 15.0 & 14.6 & 15.0 & 0.3 & 0.840 \\
Drip loss at 24 h $(\mathrm{g} / \mathrm{kg})$ & 104.1 & 92.8 & 86.5 & 4.5 & 0.269 \\
Drip loss at 48 h $(\mathrm{g} / \mathrm{kg})$ & 133.4 & 120.2 & 114.0 & 4.1 & 0.122 \\
Cooking loss $(\mathrm{g} / \mathrm{kg})$ & 214.0 & 201.9 & 206.0 & 4.8 & 0.552 \\
Thigh & & & & & \\
pH45min & 6.32 & 6.37 & 6.42 & 0.04 & 0.576 \\
pH $24 \mathrm{~h}$ & 6.17 & 6.31 & 6.17 & 0.03 & 0.072 \\
Lightness & $51.1^{\mathrm{a}}$ & $48.1^{\mathrm{b}}$ & $49.2^{\mathrm{ab}}$ & 0.5 & 0.047 \\
Redness & 6.67 & 7.11 & 6.31 & 0.21 & 0.308 \\
Yellowness & 14.0 & 15.4 & 13.8 & 0.4 & 0.182 \\
Drip loss at $24 \mathrm{~h}(\mathrm{~g} / \mathrm{kg})$ & $102.5^{\mathrm{a}}$ & $67.3^{\mathrm{b}}$ & $72.9^{\mathrm{b}}$ & 6.3 & 0.023 \\
Drip loss at $48 \mathrm{~h}(\mathrm{~g} / \mathrm{kg})$ & $120.1^{\mathrm{a}}$ & $96.9^{\mathrm{ab}}$ & $85.2^{\mathrm{b}}$ & 5.7 & 0.027 \\
Cooking loss $(\mathrm{g} / \mathrm{kg})$ & 273.3 & 232.6 & 263.4 & 8.3 & 0.109 \\
\hline
\end{tabular}

SEM, pooled standard error of the means.

${ }^{1}$ Control, basal diet; SVE, basal diet supplemented with $20 \mathrm{IU} / \mathrm{kg}$ synthetic vitamin E; NVE, basal diet supplemented with $20 \mathrm{IU} / \mathrm{kg}$ natural vitamin E.

${ }^{a-b}$ Means within a row with different superscripts are different at $\mathrm{p}<0.05$.

Bartov and Frigg (1992). Recently, Rey et al. (2015) have also demonstrated that performance parameters were not modified by source (natural vs synthetic) and dosage of vitamin $\mathrm{E}$ in turkeys. It has been reported that supplementation of vitamin $\mathrm{E}$ ( $\alpha$-tocopherol) from 0 to 100 $\mathrm{mg} / \mathrm{kg}$ did not alter growth performance of chicks given a maize-soya bean meal-soya oil type diet, and it may be due to the fact that vitamin $\mathrm{E}$ content in the basal diet $(\alpha$ tocopherol content in grower and finisher diet was 7 and 6 $\mathrm{mg} / \mathrm{kg}$, respectively) would meet the requirement of broilers (Guo et al., 2001). The similar growth performance among

Table 6. Effects of natural and synthetic vitamin E on antioxidant status of meat in broilers

\begin{tabular}{|c|c|c|c|c|c|}
\hline Items & Control $^{1}$ & SVE & NVE & SEM & p-value \\
\hline \multicolumn{6}{|l|}{ Breast } \\
\hline MDA (nmol/mg protein) & $0.70^{\mathrm{a}}$ & $0.30^{\mathrm{b}}$ & $0.23^{\mathrm{b}}$ & 0.07 & 0.022 \\
\hline GSH-PX (U/mg protein) & 12.8 & 14.1 & 16.3 & 0.8 & 0.163 \\
\hline T-AOC (U/mg protein) & 0.26 & 0.24 & 0.24 & 0.01 & 0.786 \\
\hline T-SOD (U/mg protein) & 51.2 & 52.7 & 50.5 & 1.6 & 0.873 \\
\hline \multicolumn{6}{|l|}{ Thigh } \\
\hline MDA (nmol/mg protein) & $0.32^{\mathrm{a}}$ & $0.27^{\mathrm{a}}$ & $0.14^{\mathrm{b}}$ & 0.03 & 0.014 \\
\hline GSH-PX (U/mg protein) & 18.4 & 25.1 & 22.5 & 1.39 & 0.136 \\
\hline T-AOC (U/mg protein) & 2.80 & 3.14 & 2.64 & 0.18 & 0.565 \\
\hline T-SOD (U/mg protein) & 39.8 & 43.0 & 40.1 & 2.00 & 0.795 \\
\hline
\end{tabular}

SEM, pooled standard error of the means; MDA, malondialdehyde; GSH-PX, glutathione peroxidase; T-AOC, total antioxidant capacity; T-SOD, total superoxide dismutase.

${ }^{1}$ Control, basal diet; SVE, basal diet supplemented with $20 \mathrm{IU} / \mathrm{kg}$ synthetic vitamin E; NVE, basal diet supplemented with 20 IU/kg natural vitamin E.

${ }^{\mathrm{a}-\mathrm{b}}$ Means within a row with different superscripts are different at $\mathrm{p}<0.05$. 
Table 7. Effects of natural and synthetic vitamin $\mathrm{E}$ on the muscular mRNA abundance of genes related to oxidative status of broilers

\begin{tabular}{cccccc}
\hline Items $^{1}$ & Control $^{2}$ & SVE & NVE & SEM & p-value \\
\hline Breast & & & & & \\
Nrf2 & 1.00 & 0.95 & 1.02 & 0.03 & 0.733 \\
HO-1 & 1.00 & 1.11 & 1.25 & 0.05 & 0.172 \\
GPX1 & 1.00 & 0.98 & 1.02 & 0.03 & 0.898 \\
SOD1 & 1.00 & 1.12 & 1.19 & 0.04 & 0.189 \\
Thigh & & & & & \\
Nrf2 & 1.00 & 1.03 & 1.04 & 0.04 & 0.911 \\
HO-1 & 1.00 & 1.19 & 1.02 & 0.04 & 0.137 \\
GPX1 & 1.00 & 1.01 & 0.97 & 0.02 & 0.669 \\
SOD1 & 1.00 & 1.18 & 0.99 & 0.04 & 0.173 \\
\hline
\end{tabular}

SEM, pooled standard error of the means; Nrf2, nuclear factor erythroid 2related factor 2; HO-1, heme oxygenase 1; SOD1, superoxide dismutase 1; GPX1, glutathione peroxidase 1 .

1 Control, basal diet; SVE, basal diet supplemented with $20 \mathrm{IU} / \mathrm{kg}$ synthetic vitamin E; NVE, basal diet supplemented with $20 \mathrm{IU} / \mathrm{kg}$ natural vitamin E.

${ }^{2}$ Expressed in arbitrary units. The mRNA level of each target gene in the control treatment was assigned a value of 1 and normalised to that of $\beta$ actin.

treatments observed in this study may also suggest that vitamin $\mathrm{E}$ in the basal diet would meet the requirement and therefore no change was detected with extra vitamin $\mathrm{E}$ supplementation.

Dietary vitamin E supplementation, irrespective of sources, increased its retention in tissues (liver and breast muscle) and plasma (Voljč et al., 2011). In this study, vitamin E supplementation in either natural (D- $\alpha$-tocopherol) or synthetic (DL- $\alpha$-tocopherol acetate) form increased $\alpha$ tocopherol accumulation in the muscles (breast and thigh), and it was consistent with the finding of Nam et al. (1997) who reported that $\alpha$-tocopherol contents of breast and thigh muscles were significantly increased by vitamin $\mathrm{E}$ supplementation. Bioavailability of vitamin $\mathrm{E}$ is related to its form. The vitamin $\mathrm{E}$ values of feed ingredients are always interpreted in terms of international units, one IU of vitamin $\mathrm{E}$ being defined as the specific activity of $1 \mathrm{mg}$ of synthetic DL- $\alpha$-tocopherol acetate, and it is generally accepted that $1 \mathrm{mg}$ of $\mathrm{D}$ - $\alpha$-tocopherol is equivalent to 1.49 IU vitamin E (McDonald et al., 2011). In this study, the capacity to increase muscular $\alpha$-tocopherol accumulation was more pronounced in the D- $\alpha$-tocopherol group. Similar results were also observed by Rey et al. (2015) in turkeys. Also, more efficient accumulation of the natural form of vitamin $\mathrm{E}$ than the synthetic form has been reported in swine (Yang et al., 2009; Amazan et al., 2014). The less efficient adsorption of the synthetic DL- $\alpha$-tocopherol acetate may account for the difference in the muscular retention (Brigelius-Flohé and Traber, 1999).

Visual appearance of fresh meat influences a consumer's decision to buy a particular meat product, and consumers usually discriminate against surface discoloration of meat. Enhanced meat color through dietary vitamin E supplementation has been demonstrated in swine (Kim et al., 2015), beef (Sherbeck et al., 1995) and poultry (Rey et al., 2015). In the present study, vitamin E supplementation increased redness of meat whereas decreased lightness of thigh. Discoloration of meat is known to be closely related with lipid peroxidation (Renerre et al., 1990; Morrissey et al., 1994; Jensen et al., 1998). The activity of the metmyoglobin reducing systems is believed to be retained for longer periods in meats with reduced lipid oxidation that resulted from vitamin E supplementation, and a positive relationship between dietary vitamin $\mathrm{E}$ and improved color stability has also been clearly demonstrated in animals (Sherbeck et al., 1995; Jensen et al., 1998). Drip loss is considered one of the major quality deterioration factors within the meat industry. Consistent with the results of O'neill et al. (1998) and Li et al. (2009), vitamin E supplementation also decreased the drip loss of thigh muscle in this study. Protection of membranal lipids against lipid oxidation by vitamin $\mathrm{E}$ has been suggested to be the mechanism responsible for the positive influence of dietary vitamin $\mathrm{E}$ on the water holding capacity since the integrity of the cell membrane is thought to be associated with drip loss (Asghar et al., 1991). MDA, the main end product of lipid peroxidation by radical oxygen species, is an important indication of lipid peroxidation. Vitamin E supplementation decreased muscular MDA accumulation. The reduced MDA accumulation was in agreement with the simultaneously enhanced $\alpha$-tocopherol retention and improved meat quality, which in turn suggested that vitamin E may improve the meat quality by enhancing muscular $\alpha$ tocopherol content which could inhibit lipid peroxidation as evidenced by reduced generation of MDA. Boler et al. (2009) and Li et al. (2009) also found that vitamin E could prevent lipid oxidation of meat by reducing the generation of thiobarbituric acid reactive substance. In this study, vitamin E supplementation did not alter the T-AOC (an indicator of total antioxidant capacity) and activities of antioxidant enzymes (SOD and GPX) that are key constituents of enzymatic antioxidant system. Similar results were also found by Voljč et al. (2011) in which neither synthetic nor natural vitamin E supplementation affected antioxidant enzymes including SOD, GPX, and glutathione reductase, and the total antioxidant status. Thus, the reduced lipid oxidation in the muscles in this study was most likely to result from enhanced $\alpha$-tocopherol retention rather than improved enzymatic antioxidant capacity. Nrf2 as a basic leucine zipper transcription factor protects the cell against oxidative stress through antioxidant response elements-mediated induction of several phase 2 detoxifying and anti-oxidant enzymes, including the HO-1, GPX1, and SOD1 (Cho et al., 2002). However, neither synthetic nor 
natural vitamin $\mathrm{E}$ supplementation altered the muscular mRNA abundances of Nrf2, HO-1, GPX1, and SOD1 in this study. Li et al. (2015) also observed that dietary vitamin E, ferulic acid or their combination supplementation did not alter mRNA expression of genes that involved in Nrf2 path way including nuclear factor erythroid 2-related factor 2antioxidant response element and GPX1 in pigs.

Vitamin E is a highly lipophilic molecule that cannot be directly dispersed into aqueous solutions. Instead, it must be incorporated into an appropriate colloidal delivery system prior to dispersion (Yang and McClements, 2013). In addition to its biological activity after consumption, encapsulation and carrier selection of vitamin $E$ have also been reported to improve its physicochemical stability during feed manufacture and storage (Reboul et al., 2006; Yang and McClements, 2013). However, the details regarding the carrier, encapsulation and other manufacture processes cannot be obtained due to commercial sensitivity. Further studies that incorporated both manufacture process and animal trials would be worthy to be conducted when evaluating the bioavailability of nature and synthetic vitamin E.

In conclusion, vitamin E supplementation had no effect on the growth performance and mRNA abundance of genes related to oxidative status of broilers. Vitamin E inclusion especially in the natural form can enhance the retention of muscular $\alpha$-tocopherol, improve meat quality and muscular antioxidant capacity.

\section{CONFLICT OF INTEREST}

We certify that there is no conflict of interest with any financial organization regarding the material discussed in the manuscript.

\section{REFERENCES}

Amazan, D., G. Cordero, C. J. López-Bote, C. Lauridsen, and A. I. Rey. 2014. Effects of oral micellized natural vitamin E (d- $\alpha-$ tocopherol) vs. synthetic vitamin $\mathrm{E}$ (dl- $\alpha$-tocopherol) in feed on $\alpha$-tocopherol levels, stereoisomer distribution, oxidative stress and the immune response in piglets. Animal 8:410-419.

Asghar, A., J. I. Gray, A. M. Booren, E. A. Gomaa, M. M. Abouzied, E. R. Miller, and D. J. Buckley. 1991. Effects of supranutritional dietary vitamin E levels on subcellular deposition of $\alpha$-tocopherol in the muscle and on pork quality. J. Sci. Food Agric. 57:31-41.

Bartov, I. and M. Frigg. 1992. Effect of high concentrations of dietary vitamin $\mathrm{E}$ during various age periods on performance, plasma vitamin $\mathrm{E}$ and meat stability of broiler chicks at 7 weeks of age. Br. Poult. Sci. 33:393-402.

Benzie, I. F. and J. J. Strain. 1996. The ferric reducing ability of plasma (FRAP) as a measure of "antioxidant power": The FRAP assay. Anal. Biochem. 239:70-76.

Boler, D. D., S. R. Gabriel, H. Yang, R. Balsbaugh, D. C. Mahan,
M. S. Brewer, F. K. McKeith, and J. Killefer. 2009. Effect of different dietary levels of natural-source vitamin $\mathrm{E}$ in growfinish pigs on pork quality and shelf life. Meat Sci. 83:723-730.

Brigelius-Flohé, R. and M. G. Traber. 1999. Vitamin E: Function and metabolism. FASEB J. 13:1145-1155.

Cho, H. Y., A. E. Jedlicka, S. P. Reddy, T. W. Kensler, M. Yamamoto, L. Y. Zhang, and S. R. Kleeberger. 2002. Role of NRF2 in protection against hyperoxic lung injury in mice. Am. J. Respir. Cell Mol. Biol. 26:175-182.

Guo, Y., Q. Tang, J. Yuan, and Z. Jiang. 2001. Effects of supplementation with vitamin $\mathrm{E}$ on the performance and the tissue peroxidation of broiler chicks and the stability of thigh meat against oxidative deterioration. Anim. Feed Sci. Technol. 89:165-173.

Hafeman, D. G., R. A. Sunde, and W. G. Hoekstra. 1974. Effect of dietary selenium on erythrocyte and liver glutathione peroxidase in the rat. J. Nutr. 104:580-587.

Halliwell, B. and J. M. C. Gutteridge. 2000. Free Radicals in Biology and Medicine. 3rd ed. Oxford Univ. Press, New York, NY, USA.

Jensen, C., C. Lauridsen, and G. Bertelsen. 1998. Dietary vitamin E: Quality and storage stability of pork and poultry. Trends Food Sci. Technol. 9:62-72.

Kaiser, M. G., S. S. Block, C. Ciraci, W. Fang, M. Sifri, and S. J. Lamont. 2012. Effects of dietary vitamin E type and level on lipopolysaccharide-induced cytokine mRNA expression in broiler chicks. Poult. Sci. 91:1893-1898.

Kim, J. C., C. G. Jose, M. Trezona, K. L. Moore, J. R. Pluske, and B. P. Mullan. 2015. Supra-nutritional vitamin E supplementation for 28 days before slaughter maximises muscle vitamin E concentration in finisher pigs. Meat Sci. 110: 270-277.

Lauridsen, C., H. Engel, S. K. Jensen, A. M. Craig, and M. G. Traber. 2002. Lactating sows and suckling piglets preferentially incorporate RRR-over all-rac- $\alpha$-tocopherol into milk, plasma and tissues. J. Nutr. 132:1258-1264.

Li, W. J., G. P. Zhao, J. L. Chen, M. Q. Zheng, and J. Wen. 2009. Influence of dietary vitamin $\mathrm{E}$ supplementation on meat quality traits and gene expression related to lipid metabolism in the Beijing-you chicken. Br. Poult. Sci. 50:188-198.

Li, Y. J., L. Y. Li, J. L. Li, L. Zhang, F. Gao, and G. H. Zhou. 2015. Effects of dietary supplementation with ferulic acid or vitamin E individually or in combination on meat quality and antioxidant capacity of finishing pigs. Asian Australas. J. Anim. Sci. 28:374-381.

Livak, K. J. and T. D. Schmittgen. 2001. Analysis of relative gene expression data using real-time quantitative PCR and the $2^{-\Delta \Delta C_{T}}$ method. Methods 25:402-408.

McDonald, P., R. A. Edwards, J. F. D. Greenhalgh, C. A. Morgan, L. A. SinclaiL, and R. G. Wilkinson. 2011. Animal Nutrition, 7th ed. Pearson, Harlow, England.

Morrissey, P. A., D. J. Buckley, P. J. Sheehy, and F. J. Monahan. 1994. Vitamin E and meat quality. Proc. Nutr. Soc. 53:289-295.

Nam, K. T., H. A. Lee, B. S. Min, and C. W. Kang. 1997. Influence of dietary supplementation with linseed and vitamin $\mathrm{E}$ on fatty acids, $\alpha$-tocopherol and lipid peroxidation in muscles of broiler chicks. Anim. Feed Sci. Technol. 66:149158.

NRC. 1994. Nutrient Requirements of Poultry. 9th rev. ed. 
National Academy Press, Washington, DC, USA.

O'neill, L. M., K. Galvin, P. A. Morrissey, and D. J. Buckley. 1998. Comparison of effects of dietary olive oil, tallow and vitamin $\mathrm{E}$ on the quality of broiler meat and meat products. Br. Poult. Sci. 39:365-371.

Ōyanagui, Y. 1984. Reevaluation of assay methods and establishment of kit for superoxide dismutase activity. Anal. Biochem. 142:290-296.

Placer, Z. A., L. L. Cushman, and B. C. Johnson. 1966. Estimation of product of lipid peroxidation (malonyl dialdehyde) in biochemical systems. Anal. Biochem. 16:359-364.

Renerre, M. 1990. Factors involved in the discoloration of beef meat. Int. J. Food Sci. Technol. 25:613-630.

Rey, A. I., J. Segura, A. Olivares, A. Cerisuelo, C. Piñeiro, and C. J. López-Bote. 2015. Effect of micellized natural (D- $\alpha-$ tocopherol) vs. synthetic (DL- $\alpha$-tocopheryl acetate) vitamin E supplementation given to turkeys on oxidative status and breast meat quality characteristics. Poult. Sci. 94:1259-1269.

Reboul, E., M. Richelle, E. Perrot, C. Desmoulins-Malezet, V. Pirisi, and P. Borel. 2006. Bioaccessibility of carotenoids and vitamin E from their main dietary sources. J. Agric. Food Chem. 54:8749-8755.

Sahin, K., N. Sahin, and M. F. Gursu. 2002. Effects of vitamins E and A supplementation on lipid peroxidation and concentration of some mineral in broilers reared under heat stress $\left(32^{\circ} \mathrm{C}\right)$. Nutr. Res. 22:723-731.

Sheehy, P. J. A., P. A. Morrissey, and A. Flynn. 1991. Influence of dietary $\alpha$-tocopherol on tocopherol concentrations in chick tissues. Br. Poult. Sci. 32:391-397.
Sherbeck, J. A., D. M. Wulf, J. B. Morgan, J. D. Tatum, G. C. Smith, and S. N. Williams. 1995. Dietary supplementation of vitamin $\mathrm{E}$ to feedlot cattle affects beef retail display properties. J. Food Sci. 60:250-252.

Voljč, M., T. Frankič, A. Levart, M. Nemec, and J. Salobir. 2011. Evaluation of different vitamin E recommendations and bioactivity of $\alpha$-tocopherol isomers in broiler nutrition by measuring oxidative stress in vivo and the oxidative stability of meat. Poult. Sci. 90:1478-1488.

Yang, H., D. C. Mahan, D. A. Hill, T. E. Shipp, T. R. Radke, and M. J. Cecava. 2009. Effect of vitamin E source, natural versus synthetic, and quantity on serum and tissue $\alpha$-tocopherol concentrations in finishing swine. J. Anim. Sci. 87:4057-4063.

Yang, Y. and D. J. McClements. 2013. Encapsulation of vitamin E in edible emulsions fabricated using a natural surfactant. Food Hydrocoll. 30:712-720.

Zhang, H., Y. Chen, Y. Li, L. Yang, J. Wang, and T. Wang. 2014. Medium-chain TAG attenuate hepatic oxidative damage in intra-uterine growth-retarded weanling piglets by improving the metabolic efficiency of the glutathione redox cycle. Br. J. Nutr. 112:876-885.

Zhang, J., Z. Hu, C. Lu, K. Bai, L. Zhang, and T. Wang. 2015. Effect of various levels of dietary curcumin on meat quality and antioxidant profile of breast muscle in broilers. J. Agric. Food Chem. 63:3880-3886.

Zhang, X. H., X. Zhong, Y. M. Zhou, H. M. Du, and T. Wang. 2009. Effect of RRR- $\alpha$-tocopherol succinate on the growth and immunity in broilers. Poult. Sci. 88:959-966. 